\title{
Is caregiver refusal of analgesics a barrier to pediatric emergency pain management? A cross-sectional study in two Canadian centres
}

\author{
Caroline Whiston, BSc*; Samina Ali, $\mathrm{MDCM}^{\dagger \neq}$; Bruce Wright, $\mathrm{MD}^{\dagger}$; David Wonnacott, $\mathrm{MD}^{*}$; \\ Antonia S. Stang, MD, MBA, MSc ${ }^{\S \uparrow ; ~ G r a h a m ~ C . ~ T h o m p s o n, ~ M D ~}{ }^{\S \uparrow ; ~ C h i r a g ~ B h a t, ~ B S c * ; ~}$ \\ Sydney Todorovich, MPH*; Ashutosh Mishra, BSc*; Dora Laczko, BSc*; Michael Miller, PhD*; \\ Naveen Poonai, MD**
}

\section{CLINICIAN'S CAPSULE}

What is known about the topic?

Children's pain in the emergency department (ED) continues to be under-recognized and sub-optimally managed. What did this study ask?

We sought to evaluate the frequency of caregiver/child acceptance of analgesia offered in the ED.

What did this study find?

Of the 743 children who presented to the ED with a painful condition, $408(54.9 \%)$ were offered analgesia. If offered in the ED, analgesia was accepted by $91 \%$ (373/408) of the caregivers/children.

Why does this study matter to clinicians?

This study suggests that caregiver/child refusal of analgesia is a not a major barrier to optimal pain management and highlights the importance of ED personnel in encouraging adequate analgesia.

\section{ABSTRACT}

Objectives: The suboptimal provision of analgesia to children in the emergency department (ED) is well-described. A yet unexplored barrier is caregiver or child refusal of analgesia. We sought to evaluate the frequency of caregiver/child acceptance of analgesia offered in the ED.

Methods: We conducted a two-centre cross-sectional study of 743 caregivers of children 4-17 years presenting to the pediatric ED with an acutely painful condition using a survey and medical record review. The primary outcome was the proportion of children/caregiver pairs who accepted analgesia in the ED.

Results: The median (IQR) age of children was 11 (7) years, and $339 / 743(45.6 \%)$ were female. The overall survey response rate was 73\% (743/1018). In the 24 hours preceding ED arrival, the median (IQR) maximal pain score rated by children and caregivers was 8/10 (4) and 5/10 (2), respectively, and $30.4 \%(226 / 743)$ of caregivers offered analgesia. In the ED, children reported a median (IQR) pain score of $8 / 10$ (2) and 54.9\% (408/743) were offered analgesia. When offered in the ED, analgesia was accepted by $91 \%$ (373/408). Overall, $55.7 \%$ (414/743) of children received some form of analgesia. Conclusions: Most caregivers/children accept analgesia when offered by ED personnel, suggesting refusal is not a major barrier to optimal management of children's pain and highlighting the importance of ED personnel in encouraging adequate analgesia. A large proportion of children in pain are not offered analgesia by caregivers or ED personnel. Educational strategies for recognizing and treating pain should be directed at children, caregivers, and ED personnel.

\section{RÉSUMÉ}

Objectif: L'offre insuffisante d'analgésiques aux enfants dans les services des urgences (SU) est un problème bien décrit dans la documentation. Toutefois, ce qui l'est moins est le refus d'analgésiques par les aidants ou par les enfants eux-mêmes. Aussi l'étude visait-elle à évaluer la fréquence de l'acceptation de l'offre d'analgésiques par les aidants ou par les enfants eux-mêmes au SU.

Méthode: Une étude transversale a été menée dans deux centres hospitaliers, à l'aide d'un questionnaire d'enquête et d'un examen de dossiers médicaux, parmi 743 aidants d'enfants âgés de 4 à 17 ans, qui ont consulté au service des urgences pédiatriques pour des affections très douloureuses. Le principal critère d'évaluation consistait en la proportion d'enfants ou d'aidants ayant accepté l'offre d'analgésiques au SU.

From the *Department of Pediatrics, Schulich School of Medicine \& Dentistry, Western University, London, ON; †Department of Pediatrics, University of Alberta, Edmonton, AB; $¥$ Women and Children's Health Research Institute, Edmonton, AB; §Departments of Pediatrics and Emergency Medicine, University of Calgary, Calgary, AB; ףAlberta Children's Hospital Research Institute, Calgary, AB; and the $\| C h i l d r e n ' s$ Health Research Institute, London Health Sciences Centre, London, ON.

Correspondence to: Dr. Naveen Poonai, Paediatric Emergency Department, Children's Hospital, London Health Sciences Centre, Schulich School of Medicine and Dentistry, 800 Commissioners Road East, London, ON, N6A 5W9; Email: naveen.poonai@Ihsc.on.ca 
Résultats: L'âge médian (écart interquartile [EIQ]) des enfants était de 11 (7) ans, et 339 enfants sur 743 (45,6\%) étaient des filles. Le taux général de réponse à l'enquête a atteint $73 \%$ (743/1018). Le score maximal médian de l'intensité de la douleur noté par les enfants et les aidants, au cours des 24 heures précédant l'arrivée au SU s'élevait respectivement à $8 / 10(4)$ et à $5 / 10(2)$, et $30,4 \%(226 / 743)$ des aidants ont offert des analgésiques. Quant au score médian (EIQ) de I'intensité de la douleur noté par les enfants au SU, il était de $8 / 10$ (2), et $54,9 \%(408 / 743)$ des enfants se sont vu offrir des analgésiques. L'offre d'analgésiques au SU a été acceptée dans 91 \% (373/408) des cas. Dans l'ensemble, 55,7 \% (414/743) des enfants ont reçu une forme quelconque d'analgésie.

Conclusions: Les résultats de l'étude démontrent que la plupart des aidants ou des enfants acceptent l'offre d'analgésiques faite par le personnel au SU, ce qui donne à penser que les refus ne constituent pas un obstacle important à la prise en charge optimale de la douleur chez les enfants et ce qui met en relief l'importance de l'offre d'une analgésie adéquate par le personnel au SU. En effet, une bonne proportion des enfants qui ressentent de la douleur ne se voient pas offrir des analgésiques par les aidants ou par le personnel au SU. Aussi faudrait-il élaborer des interventions de formation sur la reconnaissance et le traitement de la douleur, spécialement conçues à l'intention des enfants, des aidants et du personnel au SU.

Keywords: opioids, pain, parent, pediatric emergency department

\section{INTRODUCTION}

Despite the passing of a Decade of Pain Control and Research (2001-2010), ${ }^{1}$ there remains abundant evidence that children's pain is sub-optimally managed in the emergency department (ED), ${ }^{2-6}$ even in conditions associated with moderate to severe pain. ${ }^{4,7,8}$ The World Health Organization has stipulated that adequate pain management is a fundamental human right, ${ }^{9}$ and the American Academy of Pediatrics reaffirmed its position that adequate analgesia should be provided for children in health care settings. ${ }^{10}$

Given recent public fears surrounding analgesia, and particularly opioids, ${ }^{11,12}$ a possible barrier to the optimal provision of analgesia in the ED is caregiver or patient refusal. Although this has not been explored to date, current evidence suggests that caregivers harbour concerns surrounding harm, ${ }^{13}$ as well as the addictive potential $^{11,14}$ of analgesics. In addition, a discrepancy exists between survey data on the high clinicianreported use of analgesia ${ }^{15,16}$ and institutional audits of practice patterns that suggest otherwise. ${ }^{17,18}$ If the refusal of analgesia were identified as a barrier to adequate pain management for children, it would provide a compelling rationale for the development of educational strategies directed at dispelling misconceptions and encouraging acceptance of analgesia offered in the ED. Alternatively, if the offering of analgesia by health care providers were shown to be the rate-limiting step, then efforts to improve this should be undertaken. Our primary objective was to determine the proportion of caregivers/children who accepted analgesia in the ED. We also sought to determine the proportion of caregivers who were offered analgesia before ED arrival, caregiver perceptions of analgesia, confidence with managing pain at home, and satisfaction with $\mathrm{ED}$ care.

\section{METHODS}

\section{Study design and setting}

This was a two-centre cross-sectional study involving a survey and medical record review (MRR). Participants were recruited over a pre-specified 16-week period from the EDs of two Canadian pediatric centres from October 13, 2015, to February 2, 2016. Because of differences in the availability of research assistants (RAs), participants were recruited consecutively for three or five days per week, between 1800 and 2300 hours. Each ED has an average annual census of 40,000 and 58,000 visits. Ethics approval was obtained from the institutional ethics review board at each site.

\section{Population}

We included caregivers in attendance of children aged 4-17 years presenting to the pediatric ED from home with a primary complaint of either headache, otalgia, sore throat, abdominal pain, or musculoskeletal (MSK) injury within 24 hours of arrival and maximal pain rated by the child of $>2 / 10$ on the Faces Pain Scale-Revised (FPS-R). ${ }^{19}$ We excluded children with a history of fever or vomiting in the previous 24 hours, chronic pain conditions, hypersensitivity to acetaminophen or ibuprofen, cognitive impairments precluding comprehension of study-related tasks, inability to tolerate oral 
medication, suspected non-accidental injury, not in attendance with a caregiver, and pregnancy. Potential participants were identified by an RA using the electronic tracking system in the ED. The RA performed eligibility screening and informed consent immediately after the bedside nursing assessment. Participants and RAs were unaware of the study hypothesis. Caregivers and patients were told that they were being surveyed to assess their opinions as to how pain should be managed prior to arrival and in the ED. RAs were told that the study was to explore the pain management practices of children at home and in the ED. They were not blinded to the survey questions but were unable to modify answers entered by participants.

\section{Survey}

The 27-item survey was developed using the approach outlined by Burns et al. ${ }^{20}$ in a de novo fashion without the use of an existing survey to guide question stems or responses. Item reduction was performed using the Delphi process. ${ }^{21}$ Following a nurse and physician assessment, we administered the first 19 questions. Immediately before discharge, we administered the final eight questions (see the Appendix). The survey was self-administered by the participant in anonymity using an iPad and hosted on the Research Electronic Data Capture (REDCap) platform. ${ }^{22}$ The caregivers completed surveys without any input from the child. Except for the child's discharge pain score, caregivers and children were blinded to each other's pain scores.

\section{Medical record review}

The MRR was limited to the physician and nursing charts and ambulance call report for the index visit. Two RAs performed the data extraction using a standardized data collection form, accompanied by a coding manual. Data were entered into a study-specific Excel spreadsheet (v. 14.3.8; Microsoft, Redmond, WA). Parameters related to the primary outcome were abstracted in duplicate, and data were double-checked for accuracy. From the MRR, we collected demographic data and type of analgesia accepted from emergency medical services (EMS) and ED personnel. It is standard practice at both sites to record medication in the medical chart, including those brought from home or used before arrival. All other outcomes were obtained from the survey.

\section{Outcomes}

The primary outcome was the proportion of children and caregivers who accepted analgesia in the ED. Secondary outcomes included: the proportion of caregivers who offered analgesia prior to ED arrival; proportion of children offered analgesia in the ED; reasons for not offering analgesia prior to arrival and refusal in the ED; beliefs regarding harm and the addictive potential of analgesia; caregiver perception of their child's pain using a 0-10 numerical rating scale (NRS); caregiver confidence in managing pain and satisfaction with care using novel five-item Likert scales (as no validated measures for these outcomes exist); children's rating of their maximal pain in the 24 hours preceding arrival to the ED, immediately following the nursing assessment, and discharge using the FPS-R; and recollection of the reassessment of pain in the ED and discharge teaching on pain management. The NRS was chosen because it is frequently used and extensively validated in both adults ${ }^{23}$ and children. ${ }^{24}$ Importantly, the NRS correlates highly with the FPS-R. ${ }^{25,26}$ The FPS-R is preferred by children, ${ }^{27}$ has been validated in children as young as four years of age, ${ }^{19}$ and is also believed to be clinically useful in older children. ${ }^{28}$ The FPS-R is scored from zero (no pain) to ten (maximal pain). ${ }^{19}$ The FPS-R and NRS were administered by the RA once the patient and caregiver had arrived into a bed.

\section{Data analysis}

Demographic, medical record, and survey data were summarized using means and standard deviations, medians and interquartile ranges (IQRs), or percentages and frequencies, as appropriate. A bivariate analysis was conducted to examine the effect of the following $a$ priori independent variables on the offering of analgesia in the ED: site, chief complaint, sex, child age, and pain score in the ED. If more than one variable was statistically significant, a multivariate analysis was performed using a stepwise logistic regression. A post hoc analysis was conducted to explore the relationship regarding the final MSK diagnosis (soft tissue injury, fracture, or dislocation) and offering analgesia in the ED. Estimates are presented as odds ratios and $p$-values with $95 \%$ confidence intervals. Data were analyzed using the SPSS statistical software package (v. 24, IBM SPSS, Armonk, New York). P-values less than 0.05 were considered statistically significant. 


\section{RESULTS}

\section{Demographics}

The proportion of participants who completed the survey was $743 / 1018(72.9 \%) ; 248$ were recruited at Site 1, and 495 were recruited at Site 2 (Figure 1). The demographic features of the caregivers and their children can be found in Table 1 .

\section{Analgesia before ED arrival}

In the 24 hours preceding ED arrival, the median (IQR) maximal pain rated by the children and caregivers was 8/10 (4) and 5/10 (2), respectively. Overall, 226/743 (30.4\%) of the caregivers were offered some form of analgesia before arrival (site 1: 68/248, 27.4\%; site 2: $158 / 495,31.9 \%)$. In all cases, it was accepted by their child. Table 2 describes reasons provided by the caregivers for not offering analgesia before arrival.

Of the 60 children who arrived by EMS, none were offered analgesia by their caregivers. EMS personnel offered analgesia to $11 / 60(18.3 \%)$ of the children, and analgesia was accepted by all but one case.

\section{Analgesia in the ED}

In the ED, the median (IQR) pain score reported by children immediately following the nursing assessment

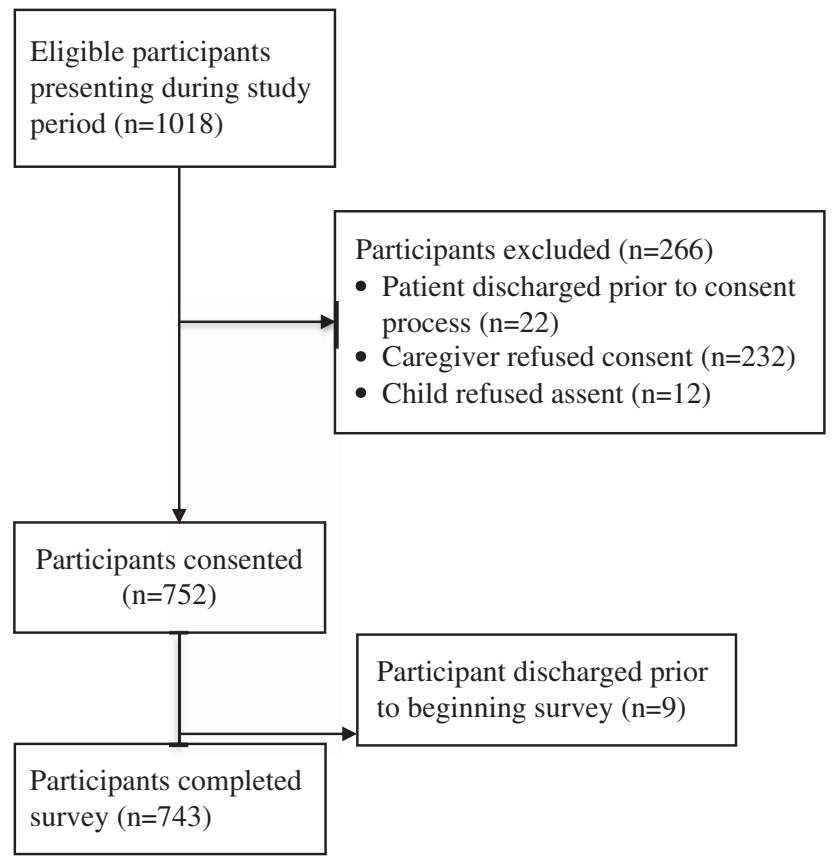

Figure 1. A flow diagram of participants. was $8 / 10$ (2). Analgesia was offered by the nurse $(330 / 743,44.4 \%)$ or physician $(78 / 743,10.5 \%)$, or it was not offered at all $(335 / 743,45.1 \%)$. If offered, analgesia was accepted by $373 / 408$ (91.4\%) of the caregivers and children. The median (IQR) time between the completion of the triage assessment to receiving analgesia was 24 (74) minutes. Analgesia included ibuprofen $(207 / 373,55.5 \%)$, other non-steroidal

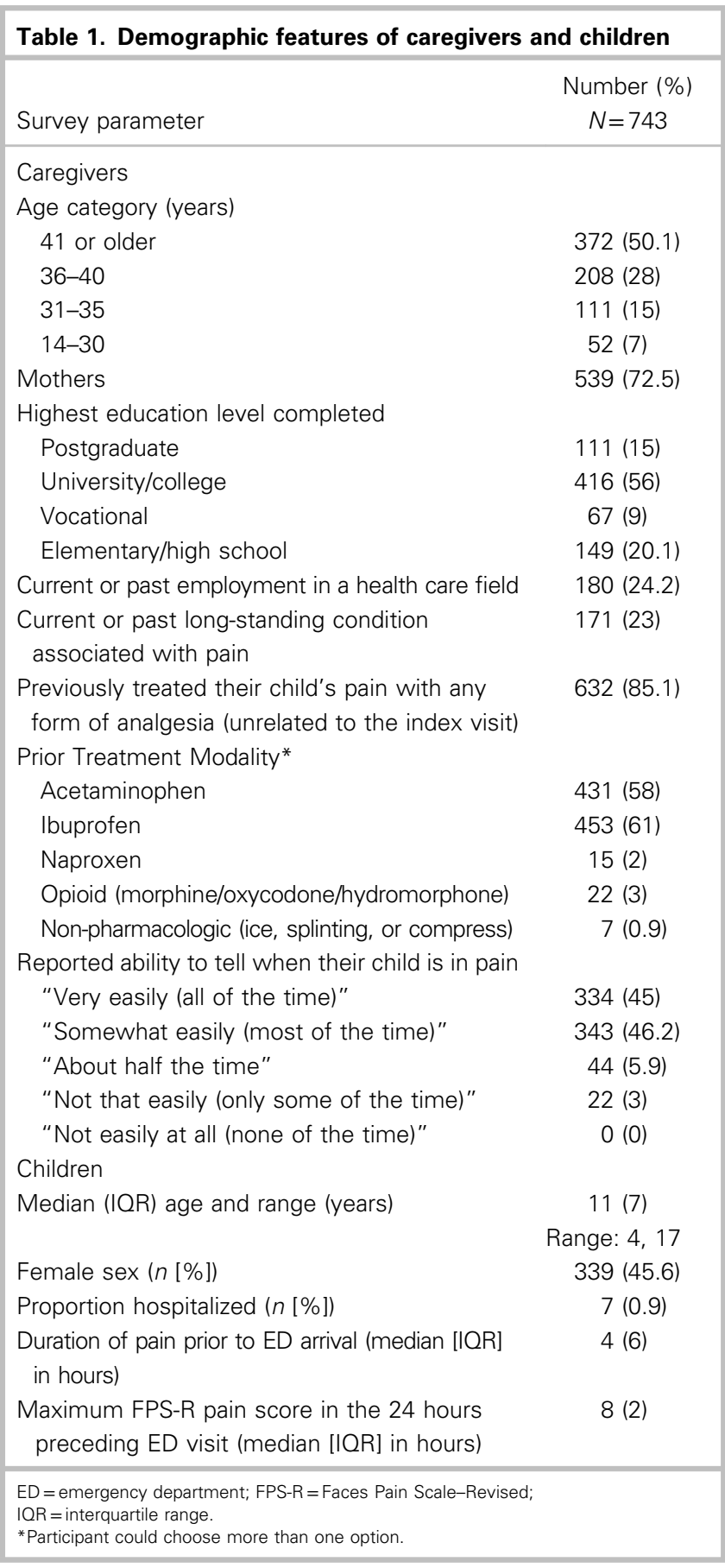




\begin{tabular}{|c|c|c|}
\hline Reason* & $\begin{array}{l}\text { Not offering analgesia prior to ED } \\
\text { arrival Number }(\%)(N=517)\end{array}$ & $\begin{array}{l}\text { Not accepting analgesia in the } \\
\text { ED Number }(\%)(N=35)\end{array}$ \\
\hline "There was no time to give medication" & $214(41.4)$ & $\mathrm{N} / \mathrm{A}$ \\
\hline $\begin{array}{l}\text { "I was worried that it would make it hard for the doctors to } \\
\text { figure out what's going on" }\end{array}$ & 98 (18.9) & $3(9)$ \\
\hline "I do not have pain medication at home or in the car" & $95(18.4)$ & $\mathrm{N} / \mathrm{A}$ \\
\hline $\begin{array}{l}\text { "I was worried that it would mask how serious my child's } \\
\text { complaint was" }\end{array}$ & $93(17.9)$ & $1(3)$ \\
\hline "I didn't think that my child was in enough pain" & $87(16.8)$ & $3(9)$ \\
\hline $\begin{array}{l}\text { "I believed that this was the job of the doctors and nurses } \\
\text { in the emergency department or paramedics" }\end{array}$ & $65(12.6)$ & $\mathrm{N} / \mathrm{A}$ \\
\hline "My child does not like taking medication" & $31(6)$ & $9(26)$ \\
\hline "I was concerned about side effects" & $20(3.9)$ & $3(9)$ \\
\hline "I thought my child should tough it out" & $9(1.7)$ & 0 \\
\hline "I don't believe that medication is all that helpful" & $9(1.7)$ & $1(3)$ \\
\hline "It did not occur to me to manage pain" & $8(2)$ & $\mathrm{N} / \mathrm{A}$ \\
\hline $\begin{array}{l}\text { "I was concerned that my child might get addicted to the } \\
\text { pain medicine" }\end{array}$ & $5(1)$ & $1(3)$ \\
\hline "I thought my child should have nothing by mouth" & $5(1)$ & $\mathrm{N} / \mathrm{A}$ \\
\hline "My child refused medication" & $2(0.4)$ & $23(66)$ \\
\hline "My child has high pain tolerance" & 0 & $8(23)$ \\
\hline $\begin{array}{l}\text { "I don't normally give my child pain medication for this } \\
\text { condition" }\end{array}$ & 0 & 1 (3) \\
\hline
\end{tabular}

anti-inflammatories (NSAIDS; 60/373, 16.1\%), acetaminophen $(35 / 373,9.4 \%)$, opioids $(29 / 373,7.8 \%)$, or non-pharmacologic therapies alone $(42 / 373,11.3 \%)$. The latter included ice alone $(21 / 373,8.3 \%)$, splinting alone $(5 / 373,1.3 \%)$, ice with splinting $(10 / 373,2.7 \%)$, and distraction with ice $(6 / 373,7.8 \%)$. Reasons for not accepting analgesia in the ED are detailed in Table 2. Overall, 414/743 (55.7\%) of the children were offered some type of analgesia by caregivers, EMS, or ED personnel. In a bivariate analysis, variables with a $p$-value of $\leq 0.05$ were included in a multivariate analysis (child age, pain score in the ED, and chief complaint). In the multivariate analysis, the overall model including chief complaint, child age, and pain score in the ED was significant $(p<0.001)$. The odds of being offered analgesia in the ED was significantly greater if the child was older (OR 1.1, 95\% CI 1.1-1.2, $p=0.04$ ), reported more severe pain in the ED (OR 1.1, 95\% CI 1.1-1.3, $p=0.04$ ), or was diagnosed with a fracture (OR 2.1, 95\% CI 1.3-3.4, $p=0.003$ ). However, the odds of being offered analgesia in the ED was significantly lower if the child presented with abdominal pain (OR 0.6 , 95\% CI $0.4-0.9, p=0.02$ )
(Table 3). Caregiver perceptions of analgesia are shown in Table 4.

\section{Confidence managing pain and satisfaction with ED care}

Of the 714 families discharged from the ED, 392 (55\%) recalled receiving education from the nurse or physician on pain management at home. The median (IQR) pain score on the FPS-R at discharge was 6/10 (4). In terms of managing their child's pain at home, caregivers reported their confidence as "very" in 493/742 (66\%), "somewhat" in 196/742 (26\%), "neutral" in 26/742 (4\%), "somewhat unsure" in $24 / 742$ (3\%), or "very unsure" in $3 / 742(1 \%)$. Caregivers rated their child's pain management in the ED as "very well" in $405 / 722$ (56\%), "somewhat well" in 98/722 (14\%), "neutral" in $167 / 722(23 \%)$, not "as well as it could have been" in $39 / 722$ (5\%), or "not well at all" in 13/722 (2\%). Caregivers rated their satisfaction with the overall care as "very satisfied" in 525/738 (71\%), "somewhat satisfied" in 143/738 (19\%), "neither satisfied nor unsatisfied" in 49/738 (7\%), "somewhat unsatisfied" in $16 / 738(2 \%)$, or "very unsatisfied" in $5 / 738(1 \%)$. 


\begin{tabular}{|c|c|c|c|c|c|}
\hline & \multicolumn{3}{|c|}{ Analgesia offered in ED } & \multicolumn{2}{|c|}{ Bivariate Analysis } \\
\hline & Yes & No & Total & OR $(95 \% \mathrm{Cl})$ & $p$-value \\
\hline \multicolumn{6}{|l|}{ Site, $n(\%)^{*}$} \\
\hline Site 2 & $262(52.9)$ & $233(47.1)$ & 495 & Reference & 0.11 \\
\hline Site 1 & $146(58.9)$ & $102(41.1)$ & 248 & $1.3(0.9,1.8)$ & \\
\hline Total & $408(54.9)$ & $335(45.1)$ & 743 & & \\
\hline \multicolumn{6}{|l|}{ Chief complaint, $n(\%)^{*}$} \\
\hline Musculoskeletal injury & $301(57.9)$ & $219(42.1)$ & 520 & $0.6(0.2,2.3)$ & \\
\hline Sprain/strain & & & 334 & Reference & \\
\hline Fracture & & & 122 & $2.1(1.3,3.3)$ & 0.002 \\
\hline Dislocation & & & 64 & $0.5(0.3,0.9)$ & 0.02 \\
\hline Abdominal pain & $51(43.6)$ & $66(56.4)$ & 117 & $0.4(0.1,0.9)$ & 0.04 \\
\hline Headache & $40(52.6)$ & $36(47.4)$ & 76 & $0.5(0.1,2)$ & 0.64 \\
\hline Otalgia & $9(45)$ & $11(55)$ & 20 & $0.4(0.1,1.8)$ & 0.33 \\
\hline Throat pain & $7(70)$ & $3(30)$ & 10 & $2.7(0.6,13.2)$ & 0.22 \\
\hline Total & $408(54.9)$ & $335(45.1)$ & 743 & & \\
\hline \multicolumn{6}{|l|}{ Sex, $n(\%)^{*}$} \\
\hline Male & $212(52.5)$ & $192(47.5)$ & 404 & Reference & \\
\hline Female & $196(57.8)$ & $143(42.2)$ & 339 & $1.3(0.9,1.7)$ & 0.14 \\
\hline Total & $408(54.9)$ & $335(45.1)$ & 743 & & \\
\hline Child age (median [(IQR]) in years & $11(6)$ & $10(7)$ & $11(7)$ & $1.1(1.1,1.2)$ & 0.03 \\
\hline ED FPS-R pain score (median [IQR]) & $10(2)$ & $8(4)$ & $8(2)$ & $1.1(1.1,1.3)$ & 0.05 \\
\hline
\end{tabular}

Table 4. Caregiver perceptions of analgesia $(N=743)$

\begin{tabular}{|c|c|c|c|c|}
\hline & $\begin{array}{l}\text { Yes } \\
n(\%)\end{array}$ & $\begin{array}{l}\text { Sometimes } \\
n(\%)\end{array}$ & $\begin{array}{l}\text { No } \\
n(\%)\end{array}$ & $\begin{array}{l}\text { Unsure } \\
n(\%)\end{array}$ \\
\hline $\begin{array}{l}\text { "Do you believe that your child can possibly become addicted to opioid medication (morphine, } \\
\text { Percocet }{ }^{\circ} \text {, or Dilaudid } ® \text { ) if used for a short time (less than five doses) in the correct dose?" }\end{array}$ & $44(6)$ & $91(12)$ & $460(62)$ & $148(20)$ \\
\hline $\begin{array}{l}\text { "Do you believe that your child can become possibly addicted to ibuprofen (Advil@ or Motrin } ® \text { ) } \\
\text { if used for a short time (less than five doses) in the correct dose?" }\end{array}$ & $7(1)$ & 21 (3) & 687 (92) & $28(4)$ \\
\hline $\begin{array}{l}\text { "Do you believe that your child can become possibly addicted to acetaminophen (Tylenol@ or } \\
\text { Tempra }(\text { ) if used for a short time (less than five doses) in the correct dose?" }\end{array}$ & $8(1)$ & 22 (3) & 691 (93) & 22 (3) \\
\hline $\begin{array}{l}\text { "Do you believe that opioid medication (morphine, Percocet }{ }^{\circledR} \text {, or Dilaudid®) can possibly cause } \\
\text { serious harm to your child if used for a short time (less than five doses) in the correct dose?" }\end{array}$ & $50(7)$ & $129(17)$ & $382(52)$ & $182(24)$ \\
\hline $\begin{array}{l}\text { "Do you believe that ibuprofen (Advil@ or Motrin } ® \text { ) can possibly cause serious harm to your child } \\
\text { if used for a short time (less than five doses) in the correct dose?" }\end{array}$ & $11(2)$ & $33(4)$ & 644 (87) & $55(7)$ \\
\hline $\begin{array}{l}\text { "Do you believe that acetaminophen (Tylenol} @ \text { or Tempra } 囚) \text { can possibly cause serious harm } \\
\text { to your child if used for a short time (less than five doses) in the correct dose?" }\end{array}$ & $24(3)$ & 37 (5) & 642 (87) & 40 (5) \\
\hline
\end{tabular}

\section{DISCUSSION}

Our results suggest that caregiver/child refusal of analgesia is likely not a major barrier to pain management in the pediatric ED. Importantly, however, the frequency of caregivers and ED personnel offering analgesia is suboptimal. Our findings underscore the need for strategies to educate children, caregivers, and ED personnel on the importance of accurate measurement and adequate management of pain both before and during acute medical care.

A large proportion of caregivers who did not offer analgesia before arrival accepted it once in the ED. This implies that caregivers look to ED providers for guidance on whether pain should be treated. For clinicians, this finding highlights the importance of offering analgesia and providing appropriate caregiver education. Refusal of analgesia has been described in a greater 
proportion (49\%) of adult ED patients, most commonly because of possible obscuration of the diagnosis. ${ }^{29}$ However, we found that children's unwillingness to take medication was the main reason for refusal. A survey of Greek school-aged children found that most believe "strongly in the therapeutic power of medicine" and obtain information from physicians, parents, and reading. ${ }^{30}$ This suggests that caregivers and clinicians are in a position to substantially influence children's perceptions on medication and educate them on the importance of expressing pain.

The proportion of caregivers offering any type of analgesia before arrival was low, even across sites, suggesting that this problem is not centre specific. Our findings are consistent with a report that only $26 \%-37 \%$ of children with MSK injuries received prehospital pharmacologic analgesia. ${ }^{31}$ This was concerning because the median FPS-R score of $8 / 10$ would be considered severe $^{32}$ and consistent with a child's perceived need for medication. ${ }^{28}$ The most common reason for not offering analgesia at home, a lack of time (41\%), was surprising given that the median duration of pain before ED arrival was four hours, possibly reflecting a social desirability bias. The prevalence of caregiver concerns regarding masking the diagnosis $(19 \%)$ and the severity of the condition (18\%) are consistent with previous findings in the context of children's MSK pain. ${ }^{31}$ Most caregivers (91\%) reported being able to tell if their child was in pain and $85 \%$ reported giving their child analgesia in the past. These findings and the fact that caregivers rated their child's pain as $5 / 10$ on the NRS (moderate pain), ${ }^{33}$ suggests that caregivers may have underestimated their child's pain. This finding must be interpreted cautiously, as there have been no studies that have explored the degree of correlation between the NRS and FPS-R for preschool children. Nevertheless, a poor correlation between parental and children's pain scores has been described $^{34-36}$ and raises the possibility that caregivers may not be able to assess the degree of their child's pain accurately. Caregivers are most often the gatekeepers to providing analgesia to children and their fears surrounding medication, particularly, opioids are prevalent, and may influence their decision-making. ${ }^{12}$ Our findings emphasize the need for strategies to educate caregivers on the importance and accurate measurement of acute pain in children so rational, evidence-informed analgesic choices can be made.

Our finding of the infrequent provision of analgesia (18\%) by EMS providers should be interpreted with caution because of regional differences in care directives. Nevertheless, previous studies have also described the suboptimal provision of analgesia to children by EMS providers. ${ }^{47,38}$ A significant barrier identified by EMS personnel is an inability to assess children's pain accurately, ${ }^{39}$ and this should be a focus of educational initiatives.

Forty-five percent of children were not offered analgesia in the $\mathrm{ED}$, consistent with a large pre-existing body of evidence. ${ }^{2,13,40-43}$ Dong et al. also reported that $59 \%$ of children with isolated long bone fractures received no analgesia within the first hour of arrival, ${ }^{8}$ and Kircher et al. reported that $62 \%$ of children with MSK injuries received no analgesia. ${ }^{4}$ In our sample, the median pain score following a nursing assessment was 8/10, highlighting the possibilities that pain was either not reassessed, reassessed but misinterpreted, or underestimated altogether. Kircher et al. also found that just over onequarter of patients in a pediatric ED had a reassessment of pain scores documented. ${ }^{4}$ Our finding that analgesia was significantly more likely to be offered if the child was older and in more severe pain is supported by robust evidence that younger children are significantly less likely to receive analgesia. ${ }^{5,7,18,44,45}$ Possible explanations include uncertainty with medication dosing, fear of adverse effects, and the inability of young children to verbalize their needs. ${ }^{5,44}$ Offering analgesia in the ED was also positively related to more severe pain. To our knowledge, this association has not been previously described and emphasizes the importance of a pain assessment upon arrival to the ED. ED staff interventions such as audit and feedback for accurate interpretation of pain scores and the importance of reassessment are important steps toward timely, effective, and consistent pain management. Not surprisingly, children presenting with abdominal pain were less likely to be offered analgesia in the ED. This is consistent with previous findings ${ }^{46-48}$ and possibly linked to a historical misconception that analgesia may mask the signs of surgical pathology. ${ }^{49,50}$ However, recent evidence has contested this belief. ${ }^{51}$

Almost one-fifth of caregivers believed opioids to be harmful and addictive, consistent with emerging literature highlighting caregiver fears surrounding analgesia, particularly opioids. ${ }^{11,12,14}$ Interestingly, a large proportion of caregivers was unsure regarding the potential for addiction (20\%) and harm (24\%) associated with opioids. These findings further emphasize the need for comprehensive caregiver education on indications for opioids and associated risks and benefits. The recent Centers for Disease Control and Prevention recommendations for opioids 
in chronic pain ${ }^{52}$ and evidence that prescription opioid use in childhood is associated with misuse as adults, ${ }^{53}$ suggesting that even clinicians need more clarity and direction on the long-term effects of short-term opioid use.

Pain severity at discharge is not predictive of caregiver satisfaction. ${ }^{54,55}$ Therefore, we assessed both global satisfaction with care and satisfaction specific to pain management. Global judgments of satisfaction with treatment is a core outcome domain outlined by the Pediatric Initiative on Methods, Measurement, and Pain Assessment in Clinical Trials (Ped-IMMPACT) consensus. ${ }^{56}$ The majority of caregivers (90\%) reported being either very or somewhat satisfied with their child's care despite ongoing pain at discharge. Importantly, a smaller proportion believed that their child's pain was managed either somewhat or very well $(70 \%)$, and almost one-quarter reported it as neutral (23\%). Although the median value of pain at discharge was $6 / 10$, constituting a clinically meaningful change from the beginning of the ED visit, ${ }^{57}$ it represents moderate pain ${ }^{32}$ and a perceived need for pharmacologic intervention., ${ }^{9,28}$ Pain relief in the ED is associated with an intent to comply with the discharge instructions, ${ }^{58}$ and caregiver satisfaction with pain management is highly correlated with pain relief in their child. ${ }^{59}$ Leaving the ED with inadequate treatment of pain is associated with suboptimal management of pain at home. ${ }^{59}$ Our findings highlight that there is room for improvement in how ED personnel manage children's pain and influence postdischarge care. This may be accomplished through previously described successful knowledge translation initiatives that incorporate education, reminders, audit, and feedback. ${ }^{60}$ Our results can likely be extrapolated across Canada because the delivery of care and structure of ED health care delivery across provinces is fairly homogenous. However, our results may not be readily generalizable to other countries where allied health personnel have different responsibilities.

\section{LIMITATIONS}

The FPS-R and NRS have not been validated for retrospective assessments and may be subject to recall bias. ${ }^{61}$ Reporting past pain may serve to convey what the individual has "endured or how they coped," possibly inflating the severity of the actual experience. However, this approach was the single best available strategy for the assessment of pre-arrival pain. It is possible that differences between parental perception of pain and pain reported by a child could have been because of different scales, but it is unlikely given the high correlation between the NRS and FPS-R. ${ }^{25,26}$ Retrospective pain assessments in children are commonly used, ${ }^{54,62}$ and although evidence specific to pain is lacking, the ability to accurately recall states such as hunger appear to be present from age four onwards. ${ }^{63}$ There is also good agreement between the pain questionnaires with a short recall interval (14 days) and prospective pain diaries. ${ }^{64}$ Global measures of confidence managing pain and satisfaction with ED care were likely dependent on factors not directly measured, such as previous experience with health care and wait time. Although others have used similar scales to measure caregiver perceptions in the context of pain, ${ }^{54}$ the results of these outcomes should be interpreted cautiously. Second, we did not record whether pain scores were documented at triage. However, no association has been found between pain score documentation at triage or the severity of pain scores and provision of analgesia to children. ${ }^{43}$ Third, our results may not reflect an actual practice setting as willing study participants might have been more motivated to manage their child's pain, and participant recruitment before physician assessment might have heightened caregiver sensitivity toward pain management. These factors may have inflated the proportion of caregivers who accepted analgesia in the ED. Finally, we were unable to determine if ED personnel reassessed pain reliably. Although this has been cited as a pervasive issue for children in the $\mathrm{ED},{ }^{3}$ reassessments might not have been documented. The fact that the median pain score at discharge was in the moderate range suggested that even if pain reassessments were performed, accurate information might not have been obtained or interpreted correctly.

\section{CONCLUSIONS}

Caregiver/child refusal of analgesia in the ED is infrequent and unlikely to be a major reason for the welldescribed suboptimal management of children's pain. However, given the possible biases associated with this study design, our estimate of the acceptance of analgesia may not apply to a practice setting outside the context of this study. Given that over $90 \%$ of caregivers accepted an offer of analgesia, ED physicians likely exert a significant influence on the pain management of children. A large proportion of children in severe pain 
are not offered analgesia by ED personnel or their caregivers. This emphasizes the need for educational interventions targeting children, caregivers, and ED personnel on the importance of adequate reporting, assessment, reassessment, and interpretation of pain scores to provide timely, effective, and universal management of pain from its onset to resolution.

Competing interests: This work was previously presented at the Canadian Association of Emergency Physicians Annual Meeting June 2016, Quebec City, QC; and American Academy of Pediatrics Annual Meeting October 2016, San Francisco, CA, USA. This study was unfunded.

\section{SUPPLEMENTARY MATERIAL}

To view supplementary material for this article, please visit https://doi.org/10.1017/cem.2018.11

\section{REFERENCES}

1. Nelson R. Decade of pain control and research gets into gear in USA. Lancet 2003 Oct;362(9390):1129.

2. Ali S, Chambers AL, Johnson DW, et al. Paediatric pain management practice and policies across Alberta emergency departments. Paediatr Child Health 2014;19(4):190-4.

3. Herd DW, Babl FE, Gilhotra Y, Huckson S. Predict g. Pain management practices in paediatric emergency departments in Australia and New Zealand: a clinical and organizational audit by National Health and Medical Research Council's National Institute of Clinical Studies and Paediatric Research in Emergency D. Emerg Med Australas 2009;21(3):210-21.

4. Kircher J, Drendel AL, Newton AS, et al. Pediatric musculoskeletal pain in the emergency department: a medical record review of practice variation. C7EM 2014; 16(6):449-57.

5. Kircher J, Drendel AL, Newton AS, et al. Acute pediatric musculoskeletal pain management in North America: a practice variation survey. Clin Pediatr (Phila) 2014;53(14): 1326-35.

6. Friedrichsdorf SJ, Postier A, Eull D, et al. Pain Outcomes in a US Children's Hospital: A Prospective CrossSectional Survey. Hosp Pediatr 2015;5(1):18-26.

7. Brown JC, Klein EJ, Lewis CW, Johnston BD, Cummings P. Emergency department analgesia for fracture pain. Ann Emerg Med 2003;42(2):197-205.

8. Dong L, Donaldson A, Metzger R, Keenan H. Analgesic administration in the emergency department for children requiring hospitalization for long-bone fracture. Pediatr Emerg Care 2012;28(2):109-14.

9. Brennan F, Carr DB, Cousins M. Pain management: a fundamental human right. Anesth Analg 2007;105(1):205-21.

10. Fein JA, Zempsky WT, Cravero JP, Committee on Pediatric Emergency Medicine and Section on Anesthesiology and Pain Medicine; American Academy of Pediatrics. Relief of pain and anxiety in pediatric patients in emergency medical systems. Pediatrics 2012;130(5):e1391-405.

11. Abou-Karam M, Dubé S, Kvann HS, et al. Parental Report of Morphine Use at Home after Pediatric Surgery. 7 Pediatr 2015;167(3):599-604.e1.

12. Basco WT. Are We Overprescribing Opioids for Pediatric Pain? Medscape; 2016. Available at: http://www.medscape. com/viewarticle/873283.

13. Spedding RL, Harley D, Dunn FJ, McKinney LA. Who gives pain relief to children? 7 Accid Emerg Med 1999; 16(4):261-4.

14. Rony RY, Fortier MA, Chorney JM, Perret D, Kain ZN. Parental postoperative pain management: attitudes, assessment, and management. Pediatrics 2010;125(6):e1372-8.

15. Poonai N, Cowie A, Davidson C, et al. Reported provision of analgesia to patients with acute abdominal pain in Canadian paediatric emergency departments. CFEM 2016; 18(5):323-30.

16. Ali S, Chambers A, Johnson DW, et al. Reported practice variation in pediatric pain management: a survey of Canadian pediatric emergency physicians. CFEM 2014; 16(5):352-60.

17. Robb AA, Poonai N, Thompson GC. Canadian Pediatric Emergency Department Pain Management for Acute Appendicitis. CFEM 2015;17(Supplement 2):S79.

18. Probst BD, Lyons E, Leonard D, Esposito TJ. Factors affecting emergency department assessment and management of pain in children. Pediatr Emerg Care 2005;21(5): 298-305.

19. Hicks CL, von Baeyer CL, Spafford PA, van Korlaar I, Goodenough B. The Faces Pain Scale-Revised: toward a common metric in pediatric pain measurement. Pain 2001;93(2):173-83.

20. Burns KE, Duffett M, Kho ME, et al. A guide for the design and conduct of self-administered surveys of clinicians. CMA7 2008;179(3):245-52. Available at: https://doi.org/10. 1503/cmaj.080372.

21. Bolger F, Wright G. Improving the Delphi process: lessons from social psychological research. Technol Forecast Soc Change 2011;78(9):1500-13.

22. Harris PA, Taylor R, Thielke R, et al. Research electronic data capture (REDCap) - a metadata-driven methodology and workflow process for providing translational research informatics support. 7 Biomed Inform 2009;42(2):377-81.

23. Dworkin RH, Turk DC, Farrar JT, et al. Core outcome measures for chronic pain clinical trials: IMMPACT recommendations. Pain 2005;113(1-2):9-19.

24. Castarlenas E, Jensen MP, von Baeyer CL, Miró J. Psychometric properties of the Numerical Rating Scale to assess self-reported pain intensity in children and adolescents: a systematic review. Clin 7 Pain 2017;33(4):376-83.

25. von Baeyer CL, Spagrud LJ, McCormick JC, et al. Three new datasets supporting use of the Numerical Rating Scale (NRS-11) for children's self-reports of pain intensity. Pain 2009;143(3):223-7.

26. Wong DL, Baker CM. Pain in children: comparison of assessment scales. Pediatr Nurs 1988;14(1):9-17.

27. de Tovar C, von Baeyer CL, Wood C, et al. Postoperative self-report of pain in children: interscale agreement, 
response to analgesic, and preference for a faces scale and a visual analogue scale. Pain Res Manag 2010;15(3): $163-8$.

28. Gauthier JC, Finley GA, McGrath PJ. Children's self-report of postoperative pain intensity and treatment threshold: determining the adequacy of medication. Clin 7 Pain 1998;14(2):116-20.

29. Allione A, Melchio R, Martini G, Dutto L, Ricca M, Bernardi E, et al. Factors influencing desired and received analgesia in emergency department. Intern Emerg Med 2011;6(1):69-78.

30. Bozoni K, Kalmanti M, Koukouli S. Perception and knowledge of medicines of primary schoolchildren: the influence of age and socioeconomic status. Eur 7 Pediatr 2006;165(1):42-9.

31. Maimon MS, Marques L, Goldman RD. Parental administration of analgesic medication in children after a limb injury. Pediatr Emerg Care 2007;23(4):223-6.

32. Tsze DS, Hirschfeld G, Dayan PS, Bulloch B, von Baeyer CL. Defining no pain, mild, moderate, and severe pain based on the faces pain scale-revised and color analog scale in children with acute pain. Pediatr Emerg Care 2016: 1, doi:10.1097/PEC.0000000000000791.

33. Collins SL, Moore RA, McQuay HJ. The visual analogue pain intensity scale: what is moderate pain in millimetres? Pain 1997;72(1-2):95-7.

34. Kelly AM, Powell CV, Williams A. Parent visual analogue scale ratings of children's pain do not reliably reflect pain reported by child. Pediatr Emerg Care 2002; 18(3):159-62.

35. Chambers CT, Reid GJ, Craig KD, McGrath PJ, Finley GA. Agreement between child and parent reports of pain. Clin 7 Pain 1998;14(4):336-42.

36. St-Laurent-Gagnon T, Bernard-Bonnin AC, Villeneuve E. Pain evaluation in preschool children and by their parents. Acta Paediatr 1999;88(4):422-7.

37. Rutkowska A, Skotnicka-Klonowicz G. Prehospital pain management in children with traumatic injuries. Pediatr Emerg Care 2015;31(5):317-20.

38. Swor R, McEachin CM, Seguin D, Grall KH. Prehospital pain management in children suffering traumatic injury. Prehosp Emerg Care 2005;9(1):40-3.

39. Rahman A, Curtis S, DeBruyne B, et al. Emergency medical services provider comfort with prehospital analgesia administration to children. Prehosp Disaster Med 2015; 30(1):66-71.

40. Todd KH, Ducharme J, Choiniere $\mathrm{M}$, et al. Pain in the emergency department: results of the pain and emergency medicine initiative (PEMI) multicenter study. 7 Pain 2007; $8(6): 460-6$.

41. Furyk J, Sumner M. Pain score documentation and analgesia: a comparison of children and adults with appendicitis. Emerg Med Australas 2008;20(6):482-7.

42. Bauman BH, McManus JG Jr. Pediatric pain management in the emergency department. Emerg Med Clin North Am 2005;23(2):393-414.

43. Weng YM, Chang YC, Lin YJ. Triage pain scales cannot predict analgesia provision to pediatric patients with longbone fracture. Am 7 Emerg Med 2010;28(4):412-7.
44. Alexander J, Manno M. Underuse of analgesia in very young pediatric patients with isolated painful injuries. Ann Emerg Med 2003;41(5):617-22.

45. Dohrenwend PB, Fiesseler FW, Cochrane DG, Allegra JR. Very young and elderly patients are less likely to receive narcotic prescriptions for clavicle fractures. Am $\mathcal{F}$ Emerg Med 2007;25(6):651-3.

46. Kim MK, Galustyan S, Sato TT, Bergholte J, Hennes HM. Analgesia for children with acute abdominal pain: a survey of pediatric emergency physicians and pediatric surgeons. Pediatrics 2003;112(5):1122-6.

47. Ayoade BA, Tade AO, Salami BA, Oladapo O. Administration of analgesics in patients with acute abdominal pain: a survey of the practice of doctors in a developing country. Int 7 Emerg Med 2009;2(4):211-5.

48. Jawaid M, Masood Z, Ayubi TK. Pre-operative analgesia in the accident and emergency department. $\mathcal{F}$ Coll Physicians Surg Pak 2009;19(6):350-3.

49. Falch C, Vicente D, Häberle H, et al. Treatment of acute abdominal pain in the emergency room: a systematic review of the literature. Eur $\mathcal{F}$ Pain 2014;18(7):902-13.

50. Nissman SA, Kaplan LJ, Mann BD. Critically reappraising the literature-driven practice of analgesia administration for acute abdominal pain in the emergency room prior to surgical evaluation. Am 7 Surg 2003;185(4): 291-6.

51. Poonai N, Paskar D, Konrad SL, et al. Opioid analgesia for acute abdominal pain in children: A systematic review and meta-analysis. Acad Emerg Med 2014;21(11): 1183-92.

52. Dowell D, Haegerich TM, Chou R. CDC Guideline for Prescribing Opioids for Chronic Pain - United States, 2016. MMWR Recomm Rep 2016;65(1 RR-1):1-49.

53. Miech R, Johnston L, O'Malley PM, Keyes KM, Heard K. Prescription opioids in adolescence and future opioid misuse. Pediatrics 2015;136(5):e1169-77.

54. Ali S, Weingarten LE, Kircher J, et al. A survey of caregiver perspectives on children's pain management in the emergency department. CFEM 2016;18(2):98-105.

55. Magaret ND, Clark TA, Warden CR, Magnusson AR, Hedges JR. Patient satisfaction in the emergency department-a survey of pediatric patients and their parents. Acad Emerg Med 2002;9(12):1379-88.

56. McGrath PJ, Walco GA, Turk DC, et al. Core outcome domains and measures for pediatric acute and chronic/ recurrent pain clinical trials: PedIMMPACT recommendations. 7 Pain 2008;9(9):771-83.

57. Bulloch B, Tenenbein M. Assessment of clinically significant changes in acute pain in children. Acad Emerg Med 2002; 9(3):199-202.

58. Downey LV, Zun LS. Pain management in the emergency department and its relationship to patient satisfaction. 7 Emerg Trauma Shock 2010;3(4):326-30.

59. Gill M, Drendel AL, Weisman SJ. Parent satisfaction with acute pediatric pain treatment at home. Clin 7 Pain 2013; 29(1):64-9.

60. Treadwell MJ, Franck LS, Vichinsky E. Using quality improvement strategies to enhance pediatric pain assessment. Int 7 Qual Health Care 2002;14(1):39-47. 
61. Noel M, Palermo TM, Chambers CT, Taddio A, Hermann C. Remembering the pain of childhood: applying a developmental perspective to the study of pain memories. Pain 2015;156(1):31-4.

62. Jaaniste T, Noel M, von Baeyer CL. Young children's ability to report on past, future, and hypothetical pain states: a cognitivedevelopmental perspective. Pain 2016;157(11):2399-409.
63. Gopnik AS, Slaughter V. Young children's understanding of changes in their mental states. Child Dev 1991;62(1):98-110.

64. Self MM, Williams AE, Czyzewski DI, Weidler EM, Shulman RJ. Agreement between prospective diary data and retrospective questionnaire report of abdominal pain and stooling symptoms in children with irritable bowel syndrome. Neurogastroenterol Motil 2015;27(8):1110-9. 